\title{
Thai-version Migraine Disability Assessment (MIDAS) questionnaire: concurrent validity, test-retest reliability, internal consistency, and factors predictive for migraine-related disability
}

Thanin Asawavichienjinda*® ${ }^{\star}$, Warangkana Imruetaijaroenchoke ${ }^{\oplus}$, Kammant Phanthumchinda ${ }^{\circledR}$

\begin{abstract}
Background: A Thai-version of the Migraine Specific Quality of Life Questionnaire (MSQ 2.1) is available, but a qualified questionnaire used specifically for disability assessment was not available. The most relevant practical disability assessment tested during this study was the Migraine Disability Assessment (MIDAS) Questionnaire.

Objectives: To test the concurrent validity, test-retest reliability, and internal consistency of a Thai-version MIDAS questionnaire, and factors to predict disability in people with migraine.

Methods: We conducted the present prospective study at a tertiary care teaching hospital in Bangkok. The original English MIDAS Questionnaire was translated into Thai with back-translation into English and the language equivalence was assessed. The Thai-version MIDAS Questionnaire was tested for concurrent validity, test-retest reliability, and internal consistency, and factors including duration of migraine history, migraine characteristics, and comorbidity were assessed for the ability to predict migraine-related disability of migraineurs.

Results: Of the 58 participants, 31 were eligible to be included. The validity of the Thai-version questionnaire between the MIDAS total score and the mean headache severity (question B), the mean pain duration per attack, and the mean pain numerical rating scale (NRS) score were moderately correlated with a Spearman correlation coefficient range $0.42-0.58$. The test-retest reliability of MIDAS grade had a weighted $\kappa$ of 0.66 , and for individual questions of the MIDAS total score, questions A and B assessed by intraclass correlation coefficients ranged 0.89-0.98. The internal consistency had a Cronbach $\alpha$ of 0.98 . The mean pain NRS score in the past 3 months was an independent predictive factor for migraine-related disability.

Conclusion: The Thai-version MIDAS Questionnaire has moderate concurrent validity, acceptable internal consistency, and excellent test-retest reliability. It would be helpful to assess clinical outcomes. Future study with a standardized translation process for the Thai-version questionnaire and a larger sample size is warranted to confirm internal consistency and determine all probable predictive factors for migraine-related disability.
\end{abstract}

Keywords: internal consistency; MIDAS Questionnaire; migraine; test-retest reliability; Thailand

*Correspondence to: Thanin Asawavichienjinda, Department of Medicine, Faculty of Medicine, King Chulalongkorn Memorial Hospital, Chulalongkorn University, 1873 Rama IV Road, Pathumwan, Bangkok 10330, Thailand, e-mail: thanin.a@chula.ac.th Department of Medicine, Faculty of Medicine, King Chulalongkorn Memorial Hospital, Chulalongkorn University, Bangkok 10330, Thailand

O Open Access. ๑ 2020 Asawavichienjinda et al., published by Sciendo. (cc) BY-NC-ND This work is licensed under the Creative Commons Attribution NonCommercial-NoDerivatives 4.0 License. 
Migraine, a primary headache disorder, is characterized differently from other types of headaches. According to the International Classification of Headache Disorders, migraine is characterized by headache with moderate or severe pain intensity accompanied by nausea/vomiting, and its worsening by physical activity [1]. This disorder has an impact on quality of life (QoL) [2], and its characteristics cause disability [3] to extents different from those of other types of headache. The disability during headache attacks, the so-called headacherelated disability [4], is defined by WHO as the consequences of illness on work and function in other roles [5]. Disability comprises impairment of body function, limitation of activity, and restriction of participation that involves a range of activities from self-care to working with capacity, and moving around at home and being able to travel or participate in sports, and pursue household activities to voting [5].

Instruments have been developed to specifically measure headache-related disability and, except for a few, have been tested for validity, internal consistency, and reliability [6-23] (shown in Table 1). These instruments can be classified into 3 groups as follows: instruments specifically measuring disability [7-9, 12, 14-17], disability and burden [18, 19], and burden alone [20-22]. The instruments specific for the disability that are applied to migraine are the Headache Impact Questionnaire (HImQ), Migraine Disability Assessment (MIDAS), and Functional Assessment In Migraine (FAIM) questionnaires. Among these questionnaires, MIDAS has moderate-to-strong criterion validity [13], acceptable internal consistency, and strong-to-very-strong reliability compared with HImQ that has weak-to-strong criterion validity and complexity in scoring [11], whereas FAIM has had no test for reliability. Only the Burden of Migraine Instrument (BURMIG) is specific for disability [18], but it has many items (77-item) and is cumbersome to administer. Only the Migraine Interictal Burden Scale (MIBS) instrument is specific for the burden of migraine [22], but it measures interictal burden, not burden during attacks. A newer, patient-reported, outcome known as Migraine Physical Function Impact Diary (MPFID) [23] was developed in 2017 after the present study was conducted in 2011-2012. The MPFID instrument measures daily disability impact on migraine days, days in between migraines, and has good convergent validity, internal consistency, and reliability. The MPFID is an alternative for clinical practice.

At the time this study was conducted, the most practical disability assessment specific for migraine was the MIDAS Questionnaire. This simple 5-item, self-administered questionairre is derived in part from and solved the practical limitations of the HImQ [12] capturing lost time from work for pay, house-work, and nonwork activities, and another
2 questions asking for total number of headache days in the past 3 months (question A) and mean headache severity (question B) [11]. It is short, easy to score and use, and provides meaningful information about lost days of activities within a 3-month timeframe [11]. The disability in people with migraine is potentially influenced by 2 major factors; one is directly related to the migraine itself and its treatments, and the other is indirectly related to the migraine such as comorbidities and their treatments. For example, depression comorbidity may cause more frequent migraine attacks, and thus cause more disability. For the migraine itself, a longer duration of headache, higher pain intensity, and more frequent migraine attacks may cause more days of lost activities per month. A MIDAS score of 0-5 days lost activity per month indicates little or no disability and is equal to MIDAS grade I; a score of 6-10 days lost activity indicates mild disability and is equal to MIDAS grade II; a score of 11-20 days lost activity indicates moderate disability and is equal to MIDAS grade III; and a score of 21 days or more indicates a severe disability and is equal to grade IV.

MIDAS also tests for sensitivity to change between episodic and chronic migraine [24] and changes between chronic migraine with a high frequency of medication use for headache ( $\geq 15$ days/month) and a low frequency of medication use ( $<15$ days/month) [25].

In Thailand, the Thai-version MSQ 2.1 has been used to assess QoL of people with migraine [26], but a translation of a questionnaire specific for assessing migraine-related disability has not been available. Two Thai versions of the MIDAS questionnaire have been published, one in 2013, and the other in 2018 [27, 28]. The first Thai questionnaire was only tested for content equivalence to the original English version by professional translators and medical specialists, but was not tested for language equivalence. In addition, the 5 items and the total score of that Thai questionnaire had only weak-to-strong criterion validity as measured by Spearman correlation coefficients and fair-to-excellent test-retest reliability as measured by intraclass correlation coefficient (ICC) [27]. Moreover, the questionnaire was not tested for internal consistency. The other Thai questionairre was only tested for test-retest reliability and internal consistency [28]. The present study fills the gaps in knowledge mentioned above and was primarily aimed at testing for concurrent validity and test-retest reliability, and secondarily at testing for internal consistency of the Thai-version MIDAS Questionnaire, and as a pilot study, for factors predictive of disability including duration of migraine history, migraine characteristics, and comorbidities for migraine-related disability as assessed by the Thai-version MIDAS Questionnaire. 
Table 1. Instruments specific for measuring headache-related disability

\begin{tabular}{|c|c|c|c|c|}
\hline Instrument & Purpose & Description & Strengths & Limitations \\
\hline \multicolumn{5}{|l|}{ Disability } \\
\hline Pain Disability Index [7] & $\begin{array}{l}\text { Unspecified chronic } \\
\text { pain }\end{array}$ & $\begin{array}{l}\text { Ability to engage in } 7 \text { categories of life } \\
\text { activities }\end{array}$ & - & Preliminary validity \\
\hline $\begin{array}{l}\text { Henry Ford Hospital } \\
\text { HDI [8] }\end{array}$ & $\begin{array}{l}\text { Nonspecific types of } \\
\text { headache }\end{array}$ & Ability to complete daily life tasks & $\begin{array}{l}\text { Good construct validity, accepta- } \\
\text { ble internal consistency, strong } \\
\text { test-retest reliability }\end{array}$ & - \\
\hline $\operatorname{HImQ}[9,10]$ & Migraine & $\begin{array}{l}\text { 16-Item: pain intensity and lost time in } \\
\text { work outside the home, in household } \\
\text { work, and nonwork activities }\end{array}$ & $\begin{array}{l}\text { Acceptable internal consistency, } \\
\text { strong test-retest correlation }\end{array}$ & $\begin{array}{l}\text { Weak to strong } \\
\text { criterion validity, } \\
\text { complexity in scoring }\end{array}$ \\
\hline $\begin{array}{l}\text { MIDAS Questionnaire } \\
{[11,12,13]}\end{array}$ & Migraine & $\begin{array}{l}\text { Simple } 5 \text {-item self-administered type } \\
\text { derived in part from and solving } \\
\text { the practical limitation of the HImQ, } \\
\text { capturing lost time from work for pay, } \\
\text { housework, and nonwork activities }\end{array}$ & $\begin{array}{l}\text { Moderate to strong criterion } \\
\text { validity, acceptable internal } \\
\text { consistency, strong to very strong } \\
\text { test-retest reliability }\end{array}$ & - \\
\hline HIT [14] & $\begin{array}{l}\text { Nonspecific types of } \\
\text { headache }\end{array}$ & $\begin{array}{l}\text { 6-Item on pain, social-role limitations, } \\
\text { cognitive functioning, psychological } \\
\text { distress, and vitality }\end{array}$ & $\begin{array}{l}\text { Good discriminant validity, } \\
\text { acceptable internal consistency, } \\
\text { excellent test-retest reliability }\end{array}$ & - \\
\hline IPDS [15] & $\begin{array}{l}\text { Chronic daily hea- } \\
\text { dache, medication } \\
\text { overuse }\end{array}$ & $\begin{array}{l}\text { 20-Item assessing beliefs regarding } \\
\text { autonomy/disability in different } \\
\text { situations of life }\end{array}$ & $\begin{array}{l}\text { Moderate to strong convergent } \\
\text { validity, acceptable internal } \\
\text { consistency }\end{array}$ & No reliability test \\
\hline HADLI [16] & $\begin{array}{l}\text { Migraine, tension- } \\
\text { type, cervicogenic } \\
\text { headaches }\end{array}$ & $\begin{array}{l}\text { 9-Item on specific activity of daily } \\
\text { living }\end{array}$ & Acceptable internal consistency & $\begin{array}{l}\text { Face validity, no } \\
\text { reliability test }\end{array}$ \\
\hline FAIM questionnaire [17] & Migraine & $\begin{array}{l}9 \text { Mental functioning items measuring } \\
\text { dimensions of attention/thought, } \\
\text { perception, and relevant } 5 \text { items of a } \\
\text { list of activities and participation }\end{array}$ & $\begin{array}{l}\text { Good convergent validity, } \\
\text { acceptable internal consistency }\end{array}$ & No reliability test \\
\hline \multicolumn{5}{|l|}{ Disability and burden } \\
\hline BURMIG [18] & Migraine & $\begin{array}{l}\text { 77-Item of burden and disability } \\
\text { obtained from MIDAS }\end{array}$ & $\begin{array}{l}\text { Acceptable construct validity, } \\
\text { acceptable internal consistency, } \\
\text { strong reliability test }\end{array}$ & - \\
\hline EUROLIGHT [19] & $\begin{array}{l}\text { Primary headache } \\
\text { disorders }\end{array}$ & $\begin{array}{l}\text { 103-Item of burden and disability } \\
\text { revised from BURMIG }\end{array}$ & $\begin{array}{l}\text { Acceptable construct validity, } \\
\text { excellent internal consistency, } \\
\text { good reliability test }\end{array}$ & - \\
\hline \multicolumn{5}{|l|}{ Burden } \\
\hline $\begin{array}{l}\text { HARDSHIP } \\
\text { questionnaire [20] }\end{array}$ & $\begin{array}{l}\text { Migraine and } \\
\text { tension-type and } \\
\text { medication overuse } \\
\text { headache }\end{array}$ & Burden measurement & Epidemiological validation & No clinical validation \\
\hline HALT [21] & $\begin{array}{l}\text { All headache dis- } \\
\text { orders }\end{array}$ & $\begin{array}{l}\text { Global burden measurement and for } \\
\text { alleviation of the burden; direct and } \\
\text { close derivative of MIDAS }\end{array}$ & Epidemiological validation & No clinical validation \\
\hline MIBS [22] & Migraine & $\begin{array}{l}\text { Interictal migraine-related burden } \\
\text { measurement in } 4 \text { domains: } \\
\text { work/school, family/social life, making } \\
\text { plans/commitments, emotional/ } \\
\text { affective/cognitive distress }\end{array}$ & $\begin{array}{l}\text { Good validity, internal consis- } \\
\text { tency and reliability test }\end{array}$ & - \\
\hline \multicolumn{5}{|c|}{ Newer instrument for disability } \\
\hline MPFID [23] & Migraine & 13-Item on daily physical functioning & $\begin{array}{l}\text { Good convergent validity, inter- } \\
\text { nal consistency, and reliability }\end{array}$ & - \\
\hline
\end{tabular}

HDI, Headache Disability Inventory; HImQ, Headache Impact Questionnaire; MIDAS, Migraine Disability Assessment; HIT, Headache Impact Test; IPDS, Italian Perceived Disability Scale; HADLI, Headache Activity of Daily Living Index; FAIM, Functional Assessment In Migraine; BURMIG, Burden of Migraine Instrument; HARDSHIP, Headache Attributed Restriction, Disability, Social Handicap, and Impaired Participation; HALT, Headache Attributed Lost Time; MIBS, Migraine Interictal Burden Scale; MPFID, Migraine Physical Function Impact Diary. 


\section{Materials and methods}

The present study was conducted with a prospective design at the Chulalongkorn Comprehensive Headache Centre at King Chulalongkorn Memorial Hospital, Faculty of Medicine, Chulalongkorn University in 2011-2012. The Chulalongkorn Institutional Review Board approved the study (approval in 2554 (2011), endorsement No. 129/2560, IRB No. 418/54).

\section{Patients}

The Chulalongkorn Comprehensive Headache Centre at King Chulalongkorn Memorial Hospital was established in 2000. This center has registered patients with headache and recorded patient information with a standardized patient record form including socioeconomic data; comorbidity; cointervention; and history of migraine headache including the history of duration, location, pain quality, pain severity, pain score, pain duration, and frequency of headache. Patients also received a headache diary to prospectively record their headaches and treatments, if any.

In the present study, we included patients who visited the center and who were diagnosed as having migraine by an attending neurologist with experience of migraine treatment according to the International Classification of Headache Disorders, second edition (ICHD-II). The inclusion criteria were patients aged 20 years or older with episodic or chronic migraine, with or without aura, who were literate in the Thai language and gave their written informed consent to participate in this study. The diagnostic criteria of migraine in this study used the criteria from the ICHD-II that was published in 2004. The present study was conducted in 2011-2012 before the ICHD-III beta version was released in 2013, and then as the ICHD-III in 2018. However, the diagnostic criteria for migraine without aura were not changed except for the diagnostic criteria for migraine with aura and chronic migraine. Migraine with aura in ICHD-II would have to fulfill one of the subforms of 1.2.1-1.2.6 that were as follows: typical aura including visual, sensory, and with dysphasic speech with migraine/nonmigraine or without a headache, familial/sporadic hemiplegic or basilartype migraine. In the ICHD-III, migraine with aura includes one or more of the following fully reversible aura symptoms: visual, sensory, speech and/or language, motor, brainstem, and retinal. The retinal aura in the ICHD-III was not included in the migraine with aura in the ICHD-II, but it was separated into another entity. The chronic migraine in the ICHD-II would have to fulfill the migraine without aura on $\geq 15$ days/month for $>3$ months. In the ICHD-III, the headache days and the duration remained the same as in the ICHD-II, but the headache characteristics could be migraine-like or tension-type-like, and on $\geq 8$ days/month for $>3$ months, the headache would have to be migraine without aura.

\section{Development of a Thai-version MIDAS questionnaire}

We received permission to use the original English MIDAS questionnaire from AstraZeneca Pharmaceuticals. It was translated into Thai by the first author (TA), a bilingual neurologist with back-translation into English by a bilingual physician with a high degree of English proficiency who was blinded to the original version and was independent of the first author. This process was repeated until the original and the back-translation were identical in content. Finally, the language equivalence of the Thai-version MIDAS Questionnaire was examined by an active informant experienced with migraine headache at the Chulalongkorn Comprehensive Headache Centre.

\section{Concurrent validity, test-retest reliability, and internal consistency of the Thai-version MIDAS questionnaire}

The Thai-version MIDAS Questionnaire and a questionnaire asking about migraine characteristics including headache frequency, mean pain duration, and mean pain intensity in the past 3 months, 2 months, 1 month, and 2 weeks were administered to patients at our headache center. Participants were asked to complete the first questionnaire at the center and to return them before leaving. They were also asked to use a headache diary to help them complete the following questionnaires. Then, before leaving the center they received the second questionnaire with to be completed at home within the following 2 weeks and requested them to mail the completed questionairre to the center in the addressed-and-stamped envelope provided for their convenince. The patients were telephoned to remind them to complete the questionnaire and return it based on the assigned date. With 2-week intervals for the mail delivery process, any second questionnaires that were missing or incomplete would be replaced with other eligible patient questionnaires until meeting the assigned the sample size. For concurrent validity, within the first questionnaire, the second, and a combination of both, the MIDAS total score in the Thai-version questionnaire was validated with the total number of headache days (question A), mean headache severity (question B), and migraine characteristics in the past 3 months. The test-retest reliability for the individual question, MIDAS total score, total number of headache days (question A), mean headache severity (question B), and Thai-version MIDAS grade were evaluated. Migraine characteristics between the 2 occasions were also evaluated to measure 
whether any differences might affect the test-retest reliability. The migraine characteristics included frequency of headache, mean attack duration, and mean pain score measured as a numerical rating scale (NRS) score. The internal consistency test of the Thai-version MIDAS Questionnaire was evaluated for each occasion.

\section{Predictive factors for migraine-related disability}

For the combination of both occasions of completing the questionnaires, duration of migraine history, comorbidity, and migraine characteristics in the past 3 months, 2 months, 1 month, and at 2 weeks were evaluated for independent predictive factors for migraine-related disability as assessed by the Thai-version MIDAS grade. The Thai-version MIDAS score is categorized into 4 grades according to the original version; grade I: little or no disability, grade II: mild disability, grade III: moderate disability, and grade IV: severe disability.

\section{Statistical analyses}

The baseline demographic and socioeconomic data and migraine characteristics between eligible and ineligible patients were compared with a Pearson $\chi^{2}$, Fisher exact, or Mann-Whitney $U$ test according to the type of data analyzed. Migraine characteristics between 2 time intervals, 3 months, 2 months, or 1 month, or 2 weeks before completing the first and the second questionnaires were analyzed using a sign test. The concurrent validity of the Thai-version MIDAS Questionnaire, on both the occasions between the MIDAS total score and question $\mathrm{A}$, question $\mathrm{B}$, and migraine characteristics during the past 3 months were tested using Spearman correlation coefficients $(\rho)$. Test-retest reliability and internal consistency of the Thai-version MIDAS Questionnaire were tested using an ICC and a Cronbach $\alpha$, respectively. Testretest reliability of the disability of the Thai-version MIDAS grade was tested for agreement using a weighted $\kappa$ statistic. Predictive factors for migraine-related disability assessed by the Thai-version MIDAS grade was tested by using bivariate analysis, Friedman, and multivariate analysis, and ordinal logistic regression. IBM SPSS Statistics for Windows (version 21.0) was used for statistical analyses. However, in the present study, we did not correct $P$-values for multiple analyses.

Sample size for test-retest reliability with a 2-tailed hypothesis tests was based upon ICC with a type I error of 0.05 , power of 0.80 , a minimally acceptable level of reliability of 0.40 , and a proposed level of reliability for this study of 0.75 [29] yielded a required sample size of 27 participants. The level of reliability of 0.40 and 0.75 was based upon guidelines described by Cicchetti [30]. The sample size for internal consistency and predictive factors was not calculated.

\section{Results}

Of the 58 participants finishing the first questionnaire, 32 mailed back the second. Of the 32 returned second questionnaires, 1 had some missing data. Therefore, 31 participants were eligible for this study (Figure 1). The baseline demographic and socioeconomic data including median years of age, male to female ratio, education, and occupation; migraine characteristics including median duration of migraine history, pain intensity, pain score, and associated symptoms; and comorbidity between those who were eligible for further analysis $(\mathrm{n}=31)$ and those who were ineligible $(\mathrm{n}=27)$ were not significantly different. Eligible patients were mostly women (97\%), with a median age of 49 years and employed (94\%) and about half of patients had less than or equal to postsecondary nontertiary education (48\%) and comorbidity (48\%). For migraine characteristics in eligible patients, the median duration of migraine history was 10 years with a high proportion $(84 \%)$ of moderate-to-severe pain intensity and mean pain score with a median NRS score of 6 , a moderate pain score. Most $(87 \%)$ had migraine-associated symptoms including nausea $(68 \%)$, vomiting $(45 \%)$, photophobia $(52 \%)$, or phonophobia (48\%) and $84 \%$ had an episodic type of migraine. Migraine without aura accounted for $68 \%$. When comparing the migraine characteristics between 3 months, 2 months, and 1 month before completing the first Thai-version MIDAS Questionnaire (Table 2), there was no significant difference in median frequency of headache per month with a median of approximately 3-4 attacks, mean pain duration per attack of a median of $2 \mathrm{~h}$, and mean pain score with a median NRS score of 5. Migraine characteristics observed in 3 months, 2 months, and 1 month, and 2 weeks between before completing the first and the second Thai-version MIDAS Questionnaire

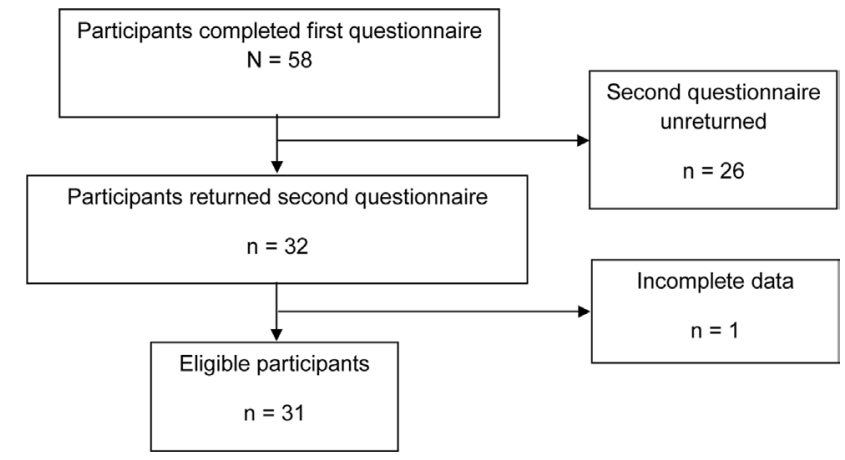

Figure 1. Diagram to report the flow of migraineur patient participants through the study. 
Table 2. Migraine characteristics in the eligible patients before completing their first Thai-version MIDAS Questionnaire

\begin{tabular}{|c|c|c|c|c|c|c|}
\hline Migraine characteristics & Past 3 - months & Past 2 - months & Past month & Pt & $P \neq$ & $P \S$ \\
\hline Frequency of headache, median attack (interquartile range) & $8(14)$ & $6(9)$ & $4(7)$ & - & - & - \\
\hline $\begin{array}{l}\text { Mean frequency of headache per month, median attack } \\
\text { (interquartile range) }\end{array}$ & $2.7(4.7)$ & $3(4.5)$ & $4(7)$ & 0.34 & 0.21 & 0.79 \\
\hline Mean pain duration per attack, median hours (interquartile range) & $2(2)$ & $2(2)$ & $2(3)$ & 0.22 & 0.18 & $>0.99$ \\
\hline Mean pain score, median NRS score (interquartile range) & $5(3)$ & $5(2)$ & $5(5)$ & 0.75 & 0.39 & 0.39 \\
\hline
\end{tabular}

MIDAS, Migraine Disability Assessment; NRS, numerical rating scale.

†Between 3 and 2 months.

¥Between 3 and 1 months.

$\S$ Between 2 and 1 months.

Table 3. Migraine characteristics before completing their first and their second Thai-version MIDAS Questionnaire

\begin{tabular}{|c|c|c|c|}
\hline Migraine characteristic & First questionnaire & Second questionnaire & $P$ \\
\hline \multicolumn{4}{|l|}{ In the past 3 months (interquartile range) } \\
\hline Frequency of headache, median attack & $8(14)$ & $9(11)$ & $>0.99$ \\
\hline Mean pain duration per attack, median hours & $2(2)$ & $2(2)$ & 0.34 \\
\hline Mean pain score, median NRS score & $5(3)$ & $5(4)$ & 0.58 \\
\hline \multicolumn{4}{|l|}{ In the past 2 months (interquartile range) } \\
\hline Frequency of headache, median attack & $6(9)$ & $6(9)$ & 0.55 \\
\hline Mean pain duration per attack, median hours & $2(2)$ & $2(2)$ & $>0.99$ \\
\hline Mean pain score, median NRS score & $5(2)$ & $5(3)$ & 0.75 \\
\hline \multicolumn{4}{|l|}{ In the past 1 month (interquartile range) } \\
\hline Frequency of headache, median attack & $4(7)$ & $4(6)$ & 0.61 \\
\hline Mean pain duration per attack, median hours & $2(3)$ & $2(2)$ & $>0.99$ \\
\hline Mean pain score, median NRS score & $5(5)$ & $5(4)$ & 0.77 \\
\hline \multicolumn{4}{|l|}{ In the past 2 weeks (interquartile range) } \\
\hline Frequency of headache, median attack & $1(3)$ & $2(4)$ & 0.22 \\
\hline Mean pain duration per attack, median hours & $1(2)$ & $1(2)$ & $>0.99$ \\
\hline Mean pain score, median NRS score & $4(1)$ & $5(3)$ & $>0.99$ \\
\hline
\end{tabular}

MIDAS, Migraine Disability Assessment; NRS, numerical rating scale.

were not significantly different (Table 3). This confirmed the stable condition of migraine characteristics of the patients before performing the first and second questionnaires because unstable conditions would interfere with the test-retest reliability.

\section{Concurrent validity of the Thai-version MIDAS questionnaire}

The MIDAS total score of the Thai-version MIDAS Questionnaire in the first completion, the second completion, and a combination of both completions was tested for validity with the total number of headache days (question A), mean headache severity (question B), and migraine characteristics in the past 3 months. The results demonstrated that the mean headache severity (question B), the mean pain duration per attack and the mean pain NRS score had a moderate correlation with the MIDAS total score with the Spearman correlation coefficients of $0.49,0.58$, and $0.49 ; 0.42,0.56$, and 0.42 ; and $0.45,0.57$, and 0.45 , respectively with the exception of the total number of headache days (question A) and frequency of headache with Spearman correlation coefficients of -0.07 to 0.20 (Table 4).

\section{Test-retest reliability and internal consistency test}

The test-retest reliability is shown in Table 5 with excellent reliability for the individual question, MIDAS total score, the 
Table 4. Concurrent validity of the total number of days from 5 questions of the Thai-version MIDAS Questionnaire, and question A, question B, and migraine characteristics in the past 3 months

\begin{tabular}{lccc}
\hline Migraine characteristics in the past 3 months & \multicolumn{2}{c}{ Total number of days from $\mathbf{5}$ questions of the Thai-version MIDAS Questionnaire } \\
\cline { 2 - 4 } & $\begin{array}{c}\text { First occasion } \\
\text { Spearman } \boldsymbol{\rho}\end{array}$ & $\begin{array}{c}\text { Second occasion } \\
\text { Spearman } \boldsymbol{\rho}\end{array}$ & $\begin{array}{c}\text { Combination of both } \\
\text { occasions Spearman } \boldsymbol{\rho}\end{array}$ \\
\hline Total number of headache days (question A) & -0.07 & 0.10 & 0.20 \\
Average headache severity (question B) & $0.49^{*}$ & $0.42^{*}$ & $0.45^{*}$ \\
Frequency of headache & -0.07 & 0.10 & 0.20 \\
Mean pain duration per attack & $0.58^{*}$ & $0.56^{*}$ & $0.57^{*}$ \\
Mean pain score, NRS & $0.49^{*}$ & $0.42^{*}$ & $0.45^{*}$ \\
\hline
\end{tabular}

MIDAS, Migraine Disability Assessment; NRS, numerical rating scale score. ${ }^{*} P<0.05$

total number of headache days (question A), mean headache severity (question B) with the ICC range 0.89-0.98 and the Thai-version MIDAS grade with weighted $\kappa$ of 0.66 . The internal consistency of the Thai-version MIDAS questionnaire at the first and the second completions was 0.98 and 0.98 , respectively.

\section{Predictive factors for migraine-related disability}

The median duration of migraine history and migraine characteristics in the past 3 months, 2 months, 1 month, and 2 weeks including frequency of headache, mean pain duration per attack and mean pain NRS for the combination of both occasions were significantly associated with migraine-related disability $(P<0.001)$ in bivariate analysis except for the comorbidity and frequency of headache and mean pain duration per attack in the past 2 weeks (Table 6). After multivariate analysis, there was only one factor that was a median of the mean pain NRS in the past 3 months being related to migrainerelated disability (Table 6).

\section{Discussion}

There have been 9 non-English versions of the MIDAS questionnaire, with Italian [31], Japanese [32], Turkish [33, 34], Taiwanese [35], Thai [27, 28], Arabic [36], Greek [37], German [38], and Spanish [39] versions that have been previously reported (Table 7). The development process for a non-English version from an original English version questionnaire included forward and backward translation. A guideline for clear and user-friendly translation, adaptation, and validation of instruments for use in cross-cultural health care research was published in 2011 [40]. In brief, step 1 for translation of the original instrument into the target language (forward translation) must be done by at least 2 independent certified bilingual, bicultural translators whose mother language is the desired target language [40]. In addition, the 2 translators must have a distinct background. Step 2 is a comparison of the 2 translated versions by a third bilingual, bicultural independent translator to resolve any ambiguities/discrepancies. Step 3 is blind back-translation done by 2 other independent, bilingual, bicultural translators with a distinct background and their mother language should be the source original language [40]. Step 4 is a comparison of the 2 back-translated versions with the same purpose as the step 2 [40]. Among the 9 non-English version MIDAS questionnaires, only one, the Germanversion has followed the described guideline for forward and backward translation. The German-version was tested for internal consistency with a Cronbach $\alpha$ of 0.69 at test and 0.67 at retest and for test-retest reliability with the ICC of $0.88-0.99$ in 36 patients with a chronic episodic headache at the pain center and general practice [38]. Italian, Greek, and Spanish versions had 2 bilingual and/or independent experts/ speakers to perform the translation, but without mentioning the translators' linguistic background. The Italian version was tested for internal consistency with a Cronbach $\alpha$ of 0.7 and test-retest reliability with a Spearman correlation coefficient of $0.54-0.77$ for the 5 questions individually, and of 0.77 for MIDAS total score in 86 people with migraine without aura at a regional headache center [31]. The Greek version was tested for convergent validity using a RAND-36 questionnaire with significantly negative correlation, for internal consistency with a Cronbach $\alpha$ of 0.71 at test and 0.82 at retest, and for test-retest reliability with an ICC of $0.41-0.81$ in 59 patients with migraine and with or without aura at 2 private clinics in Athens [37]. The Spanish version was tested for concurrent validity with headache frequency with Spearman $\rho$ of 0.53 , with headache intensity with a Spearman $\rho$ of 0.34 ; for internal consistency with a Cronbach $\alpha$ of 0.79 and for testretest reliability with an ICC of $0.63-0.90$ in 153 university 
Table 5. Test-retest reliability of the Thai-version MIDAS Questionnaire

\begin{tabular}{lcc}
\hline Thai-version MIDAS score & First questionnaire & Second questionnaire \\
\hline 1. "On how many days in the last 3 months did you miss & work or school because of your headaches?" & \\
Mean (SD) & $1.4(3.93)$ & $1.5(4.00)$ \\
Median & 0 & 0 \\
Min-max & $0-21$ & $0-21$ \\
\hline
\end{tabular}

2. "How many days in the last 3 months was your productivity at work or school reduced by half or more because of your headaches? (Do not include days you counted in question 1 where you missed work or school.)"

$\begin{array}{lccc}\text { Mean (SD) } & 1.8(4.30) & 1.5(3.90) & 0.95 \\ \text { Median } & 0 & 0 & 0-21 \\ \text { Min-max } & 0-21 & 0\end{array}$

3. "On how many days in the last 3 months did you not do household work (such as housework, home repairs and maintenance, shopping, caring for children and relatives) because of your headaches?"

\begin{tabular}{|c|c|c|c|}
\hline Mean (SD) & 1.4 (3.97) & $1.0(3.83)$ & 0.95 \\
\hline Median & 0 & 0 & \\
\hline Min-max & $0-21$ & $0-21$ & \\
\hline
\end{tabular}

4. "How many days in the last 3 months was your productivity in household work reduced by half or more because of your headaches? (Do not include days you counted in question 3 where you did not do household work.)"

\begin{tabular}{|c|c|c|c|}
\hline Mean (SD) & 1.7 (3.95) & $1.7(4.07)$ & 0.94 \\
\hline Median & 0 & 0 & \\
\hline Min-max & $0-21$ & $0-21$ & \\
\hline
\end{tabular}

5. "On how many days in the last 3 months did you miss family, social, or leisure activities because of your headaches?"

\begin{tabular}{lcc} 
Mean (SD) & $1.5(3.94)$ & $1.1(3.83)$ \\
Median & 0 & 0 \\
Min-max & $0-21$ & $0-21$ \\
\hline Total number of days from 5 questions & & \\
Mean (SD) & $7.8(19.50)$ & $6.8(19.03)$ \\
Median & 0 & 0 \\
Min-max & $0-105$ & $0-105$ \\
\hline
\end{tabular}

A. "On how many days in the last 3 months did you have a headache? (If a headache lasted more than 1 day, count each day.)"

\begin{tabular}{lcc} 
Mean (SD) & $18.4(25.73)$ & $17.7(24.99)$ \\
Median & 8 & 9 \\
Min-max & $1-90$ & $1-90$ \\
\hline B. “On a scale of 0 to 10, on average how painful were these headaches? (where $0=$ no pain at all, and $10=$ pain as bad as it can be)” \\
Mean (SD) & $5.5(2.15)$ & $5.6(2.23)$ \\
Median & 5 & 5 \\
Min-max & $1-10$ & $1-10$ \\
\hline Grade I & $22(71 \%)$ & $23(71 \%)$ \\
Grade II & $3(10 \%)$ & $4(13 \%)$ \\
Grade III & $2(7 \%)$ & $4(13 \%)$ \\
Grade IV & $4(13 \%)$ & $1(3 \%)$ \\
\hline
\end{tabular}

The Thai-version MIDAS score is categorized into 4 grades according to the original version, grade I: little or no disability, grade II: mild disability, grade III: moderate disability, and grade IV: severe disability.

ICC, intraclass correlation coefficient; MIDAS, Migraine Disability Assessment.

tWeighted $\kappa$. 
Table 6. Factors predictive of migraine disability

\begin{tabular}{|c|c|c|}
\hline \multirow[t]{2}{*}{ Duration of migraine history, migraine characteristics, and comorbidities } & \multicolumn{2}{|c|}{ Thai-version MIDAS grade } \\
\hline & Bivariate analysis $P$ & Multivariate analysis $P$ \\
\hline Median duration of migraine history & $<0.001$ & 0.35 \\
\hline Having comorbidities & 0.30 & - \\
\hline \multicolumn{3}{|l|}{ In the past 3 months } \\
\hline Frequency of headache, median attack & $<0.001$ & $>0.99$ \\
\hline Average pain duration per attack, median hours & $<0.001$ & 0.73 \\
\hline Average pain score, median NRS score & $<0.001$ & 0.007 \\
\hline \multicolumn{3}{|l|}{ In the past 2 months } \\
\hline Frequency of headache, median attack & $<0.001$ & 0.76 \\
\hline Average pain duration per attack, median hours & $<0.001$ & 0.95 \\
\hline Average pain score, median NRS score & $<0.001$ & 0.13 \\
\hline \multicolumn{3}{|l|}{ In the past 1 month } \\
\hline Frequency of headache, median attack & $<0.001$ & 0.33 \\
\hline Average pain duration per attack, median hours & 0.001 & 0.14 \\
\hline Average pain score, median NRS score & $<0.001$ & 0.56 \\
\hline \multicolumn{3}{|l|}{ In the past 2 weeks } \\
\hline Frequency of headache, median attack & 0.23 & - \\
\hline Average pain duration per attack, median hours & 0.73 & - \\
\hline Average pain score, median NRS score & $<0.001$ & 0.86 \\
\hline
\end{tabular}

MIDAS, Migraine Disability Assessment; NRS, numerical rating scale.

undergraduate and graduate students diagnosed as having migraine [39]. For other versions with one translator for each process, or without mentioning the process, the Japanese version was tested for criterion validity with diary-based measures with a correlation coefficient of $0.36-0.66$ for the 5 questions individual and of 0.66 for MIDAS total score and test-retest reliability with Spearman correlation coefficients of $0.59-0.80$ for the 5 individual questions and of 0.83 for MIDAS total score in 99 people with headache, and just more than half of them $(50.5 \%)$ were diagnosed with migraine at a neurological department and an affiliated clinic [32]. A Turkish version was tested for the validity of the MIDAS total score with the number of days with headache with a Spearman $\rho$ of $0.60,0.47$, and 0.63 at the first, the second, and the third visit, respectively; with internal consistency having a Cronbach $\alpha$ of $0.73,0.87$, and 0.86 at the first, the second and the third visit, respectively; and test-retest reliability with a Spearman $\rho$ of 0.68 for MIDAS total score in people with migraine at 17 neurology clinics [33]. Another Turkish version was tested for validity with diary-based measures with correlation coefficients of 0.54-0.89 for individual questions and MIDAS total score among 3 occasions, internal consistency with a Cronbach $\alpha$ of 0.78-0.90 among questions and 3 occasions, and testretest reliability with Spearman correlation coefficients of $0.66-0.81$ for each of the 5 questions in 60 people with migraine at a headache center [34]. A Taiwanese version was tested for validity with the total number of headache days and headache severity with a correlation coefficient of 0.37 and 0.34, respectively; internal consistency with a Cronbach $\alpha$ of 0.79 and test-retest reliability with Spearman correlation coefficients of $0.48-0.73$ for the 5 individual questions and of 0.67 for MIDAS total score in 31 people with migraine at a headache clinic [35]. A Thai version was tested for criterion validity with 13 -week diary data with correlation coefficients of $0.32-0.74$ for 5 individual questions, the number of headache days and pain severity and test-retest reliability with ICC of $0.58-0.82$ for the 5 individual questions and of 0.76 for the MIDAS total score in 93 people with migraine for validity test and 30 for test-retest reliability at a headache clinic conducted between October 2010 and September 2011 [27], the study time straddling the release of the new guidelines in 2011. The other Thai version was assessed for test-retest reliability with correlation coefficients ranging from 0.36 to 0.94 and for internal consistency with an ICC of 0.95 [28]. Among all of the non-English versions, 6 versions were tested for validity, internal consistency, and test-retest reliability [33-37, 39]. Only 2 Turkish versions [33, 34], had moderateto-strong validity (Spearman correlation coefficients of 
Table 7. Summary translation process, validity, internal consistency, and test-retest reliability of non-English MIDAS questionnaires

\begin{tabular}{|c|c|c|c|c|c|}
\hline Version & Forward translation & Backward translation & $\begin{array}{l}\text { Validity correlation } \\
\text { coefficient }\end{array}$ & $\begin{array}{l}\text { Internal consistency } \\
\text { Cronbach a }\end{array}$ & $\begin{array}{l}\text { Test-retest reliabi- } \\
\text { lity Spearman } \rho\end{array}$ \\
\hline Italian [31] & Two independent & Two different experts & Not mentioned & 0.7 & $0.54-0.77$ \\
\hline Japanese [32] & Not mentioned & Not mentioned & $0.36-0.88$ & Not mentioned & $0.59-0.83$ \\
\hline Turkish 1 [33] & Not mentioned & Not mentioned & $0.47-0.63$ & $0.73-0.87$ & 0.68 \\
\hline Turkish 2 [34] & A physician & A neurologist & $0.54-0.89$ & $0.78-0.90$ & $0.66-0.81$ \\
\hline Taiwanese [35] & $\begin{array}{l}\text { Following standard } \\
\text { technique, not detailed }\end{array}$ & $\begin{array}{l}\text { Following standard tech- } \\
\text { nique, not detailed }\end{array}$ & $0.34-0.37$ & 0.79 & $0.48-0.73$ \\
\hline Thai [27] & Three; one professional & One professional & $0.32-0.74$ & Not mentioned & $0.58-0.82 \dagger$ \\
\hline Thai [28] & $\begin{array}{l}\text { Two; one neurologist, } \\
\text { another native speaker }\end{array}$ & One fluent in English & Not tested & $0.95+$ & $0.36-0.94$ \\
\hline Arabic [36] & One professional & Independent professional & $0.71-0.92$ & $0.86,0.96$ & $0.97-0.99 \dagger$ \\
\hline Greek [37] & Two bilingual speakers & Two bilingual speakers & $\begin{array}{l}\text { Correlation with } \\
\text { RAND-36 }\end{array}$ & $0.71,0.82$ & $0.41-0.81 \dagger$ \\
\hline German [38] & $\begin{array}{l}\text { Two bilingual indepen- } \\
\text { dent different back- } \\
\text { ground }\end{array}$ & $\begin{array}{l}\text { Two bilingual independent } \\
\text { different background }\end{array}$ & Not mentioned & $0.69,0.67$ & $0.88-0.99 \dagger$ \\
\hline Spanish [39] & $\begin{array}{l}\text { Two bilingual indepen- } \\
\text { dent experts }\end{array}$ & Two bilingual experts & $0.53,0.34$ & 0.79 & $0.63-0.90 \dagger$ \\
\hline Present study & Bilingual neurologist & $\begin{array}{l}\text { Another bilingual physician } \\
\text { with blinding and } \\
\text { independence }\end{array}$ & $0.45-0.57 \ddagger$ & 0.98 & $0.89-0.98+$ \\
\hline MIDAS grade & & & & & $0.66 \S$ \\
\hline
\end{tabular}

MIDAS, Migraine Disability Assessment.

†Intraclass correlation coefficient.

¥Mean headache severity (question B), mean pain duration per attack and numerical rating scale score.

§Weighted $\kappa$.

0.40-0.59 considered moderate, and $0.60-0.79$ considered strong) and had strong-to-very strong test-retest reliability, but both were in between acceptable and unacceptable for internal consistency (Cronbach $\alpha$ across 0.8).

In the present study, the process involving the forward and backward translation of the Thai-version language questionnaire was a limitation and this study conducted in 2011-2012 in the midst of the release of the new translation guidelines in 2011 [40]. However, the patients who participated were typical and would generally represent people with migraine. Most had episodic migraine with a median frequency 3-4 attacks of headache per month and were mostly stable in migraine conditions (Table 3), prerequisite conditions, for test-retest reliability test of the Thai-version MIDAS Questionnaire. The median pain duration per attack was $2 \mathrm{~h}$ and pain NRS score of 5 between 3 months, 2 months, and 1 month. The median pain duration of $2 \mathrm{~h}$ in the present study might have been modified by taking acute pain medications. One of the criteria for the diagnosis of migraine is the pain duration between 4-72 h without treatment or with unsuccessful treatment [1]. The confirmation of stable migraine conditions among these participants includes: the migraine characteristics in the past 3 months, 2 months, 1 month, and 2 weeks before completing the first and the second questionnaire (Table 3) was very similar, which would yield excellent test-retest reliability of the questionnaire, ICC of 0.94-0.95 for individual questions, ICC of 0.98 for MIDAS total score, ICC of 0.97 for question A, ICC of 0.89 for question $B$, and weighted $\kappa$ of 0.66 (substantial agreement) for MIDAS grade. The Thai-version MIDAS Questionnaire also had acceptable internal consistency, with a Cronbach $\alpha$ of 0.98 .

The concurrent validity of the Thai-version MIDAS Questionnaire between the MIDAS total score and mean headache severity (question B) was moderately correlated. The concurrent validity between the MIDAS total score and the mean pain duration per attack and the mean pain NRS was also moderately correlated. However, the concurrent validity between the MIDAS total score and the total number of headache days (question A) and the frequency of headache was very weak or weakly correlated. These results imply that even though the total number of headache days and the frequency of headache were higher, which includes the short 
pain duration per attack and the low pain score, the headache may not interfere with daily activities. By contrast, when total numbers of headache days were few, but were with long pain duration and high pain score, the migraine would interfere with daily activities causing lost days.

Interestingly, factors predictive for migraine-related disability in the present study were the median of the mean pain NRS score in the past 3 months as an independent predictive factor for migraine-related disability. The frequency of headache at any period was not predictive for migraine disability. This supports the hypothesis that the frequency of headache is not correlated with the MIDAS total score that counts missed daily activities and is not a predictor for migraine disability. To determine whether other factors that were not shown to be predictive for migraine-related disability, a study with a larger sample size should be conducted. Migraine prevention might have an effect on migraine-related disability and is a limitation of this study.

This study had some other limitations including the translation process for the Thai-version questionnaire, a lack of sample size calculation for the internal consistency test, not including migraine treatment in the analysis of factors predictive for migraine-related disability, and not adjusting $P$-values for multiple analyses.

\section{Conclusions}

The present Thai-version MIDAS Questionnaire had moderate concurrent validity, acceptable internal consistency, and excellent test-retest reliability. It would be helpful to assess clinical outcomes. Future study with a standardized translation process for the Thai language questionnaire and larger sample size are required to confirm internal consistency and determine other factors predictive for migraine-related disability.

Author contributions. All authors contributed substantially to the conception and design of the study, TA and WI curated the data and contributed to its analysis and interpretation. TA and WI drafted the original manuscript and TA and KP critically revised it. All authors approved the final version submitted for publication and take responsibility for the statements made in the published article.

Acknowledgments. The authors thank AstraZeneca Pharmaceuticals (Alderley Park, Cheshire, United Kingdom), who were involved in the development of the original English language version, for permission to utilize the instrument entitled the "Migraine Disability Assessment Questionnaire". We did not receive any specific grant for this research from any funding agencies in the public, commercial, or not-forprofit sectors. The authors had full access to all of the data in this study and take complete responsibility for the integrity of the data and the accuracy of the data analysis.

Conflict of interest statement. The authors have each completed and submitted an International Committee of Medical Journal Editors Uniform Disclosure Form for Potential Conflicts of Interest. No financial of nonfinancial benefits have been or will be received from any party related directly or indirectly to the subject of the article. None of the authors have any relationships, conditions, or circumstances that present a potential conflict of interest to disclose in relation to the present article.

Data sharing statement. Any data produced during the course of the present study will be shared by the authors on reasonable request after deidentification of data from any individual patient.

\section{References}

[1] Headache Classification Committee of the International Headache Society (IHS). The international classification of headache disorders, 3rd edition (beta version). Cephalalgia. 2013; 33:629-808.

[2] Freitag FG. The cycle of migraine: patients' quality of life during and between migraine attacks. Clinical Therapy 2007; 29:939-49.

[3] World Health Organization. The world health report - 2001: mental health, new understanding new hope [Internet]. Geneva: World Health Organization; 2001 [cited 2020 April 24]. Available from: https://www.who.int/whr/2001/en/

[4] National Academy of Sciences/Institute of Medicine (NAS/IOM). Disability in America: toward a national agenda for prevention. Washington, DC: NAS Press; 1991.

[5] Leonardi M, Steiner TJ, Scher AT, Lipton RB. The global burden of migraine: measuring disability in headache disorders with WHO's Classification of Functioning, Disability and Health (ICF). J Headache Pain. 2005; 6:429-40.

[6] Buse DC, Sollars CM, Steiner TJ, Jensen RH, Al Jumah MA, Lipton RB. Why HURT? A review of clinical instruments for headache management. Curr Pain Headache Rep. 2012; 16:237-54.

[7] Pollard CA. Preliminary validity study of the pain disability index. Percept Mot Skills. 1984; 59:974.

[8] Jacobson GP, Ramadan NM, Aggarwal SK, Newman CW. The Henry Ford Hospital Headache Disability Inventory (HDI). Neurology. 1994; 44:837-42.

[9] Stewart WF, Lipton RB, Simon D, Liberman J, Von Korff M. Validity of an illness severity measure for headache in a population sample of migraine sufferers. Pain. 1999; 79:291-301.

[10] Stewart WF, Lipton RB, Simon D, Von Korff M, Liberman J. Reliability of an illness severity measure for headache in a population sample of migraine sufferers. Cephalalgia. 1998; 18:44-51.

[11] Stewart WF, Lipton RB, Whyte J, Dowson A, Kolodner K, Liberman JN, Sawyer J. An international study to assess reliability 
of the migraine disability assessment (MIDAS) score. Neurology. 1999; 53:988-94.

[12] Stewart WF, Lipton RB, Kolodner K, Liberman J, Sawyer J. Reliability of the migraine disability assessment score in a population-based sample of headache sufferers. Cephalalgia. 1999; 19:107-14.

[13] Stewart WF, Lipton RB, Kolodner KB, Sawyer J, Lee C, Liberman JN. Validity of the migraine disability assessment (MIDAS) score in comparison to a diary-based measure in a population sample of migraine sufferers. Pain. 2000; 88:41-52.

[14] Kosinski M, Bayliss MS, Bjorner JB, Ware JE Jr, Garber WH, Batenhorst A, et al. A six-item short-form survey for measuring headache impact: the HIT-6. Qual Life Res. 2003; 12:963-74.

[15] Innamorati M, Pompili M, De Filippis S, Gentili F, Erbuto D, Lester D, et al. The validation of the Italian Perceived Disability Scale (IPDS) in chronic daily headache sufferers. J Headache Pain. 2009; 10:21-6.

[16] Vernon H, Lawson G. Development of the headache activities of daily living index: initial validity study. J Manipulative Physiol Ther. 2015; 38:102-11.

[17] Pathak DS, Chisolm DJ, Weis KA. Functional assessment in migraine (FAIM) questionnaire: development of an instrument based upon the WHO's International Classification of Functioning, Disability, and Health. Value Health. 2005; 8:591-600.

[18] Andrée C, Vaillant M, Rott C, Katsarava Z, Sándor PS. Development of a self-reporting questionnaire, BURMIG, to evaluate the burden of migraine. J Headache Pain. 2008; 9:309-15.

[19] Andrée C, Vaillant M, Barre J, Katsarava Z, Lainez JM, Lair ML, et al. Development and validation of the EUROLIGHT questionnaire to evaluate the burden of primary headache disorders in Europe. Cephalalgia. 2010; 30:1082-100.

[20] Steiner TJ, Gururaj G, Andrée C, Katsarava Z, Ayzenberg I, Yu SY, et al. Diagnosis, prevalence estimation and burden measurement in population surveys of headache: presenting the HARDSHIP questionnaire. J Headache Pain. 2014; 15:3. doi: 10.1186/11292377-15-3

[21] Steiner TJ. The HALT and HART indices. J Headache Pain. 2007; 8:S22-25.

[22] Buse DC, Bigal MB, Rupnow M, Reed M, Serrano D, Lipton RB. Development and validation of the migraine interictal burden scale (MIBS): a self-administered instrument for measuring the burden of migraine between attacks [abstract S05.003]. Neurology. 2007; 68(Suppl 1):A89.

[23] Kawata AK, Hsieh R, Bender R, Shaffer S, Revicki DA, Bayliss M, et al. Psychometric evaluation of a novel instrument assessing the impact of migraine on physical functioning: the migraine physical function impact diary. Headache. 2017; 57:1385-98.

[24] Buse DC, Manack AN, Fanning KM, Serrano D, Reed ML, Turkel CC, Lipton RB. Chronic migraine prevalence, disability, and sociodemographic factors: results from the American Migraine Prevalence and Prevention Study. Headache. 2012; 52:1456-70.

[25] Suh GI, Park JW, Shin HE. Differences in clinical features and disability according to the frequency of medication use in patients with chronic migraine. J Clin Neurol. 2012; 8:198-203.
[26] Asawavichienjinda T, Vorasayan P, Noiwattanakul J, Phanthumchinda K. Validity, reliability and sensitivity to change of the Thai-version Migraine Specific Quality of Life Questionnaire (MSQ 2.1). Asian Biomed (Res Rev News). 2017; 11:331-42.

[27] Seethong P, Nimmannit A, Chaisewikul R, Prayoonwiwat N, Chotinaiwattarakul W. Reliability and validity of migraine disability assessment questionnaire-Thai version (Thai-MIDAS). J Med Assoc Thai. 2013; 96(Suppl 2):S29-38.

[28] Vongvaivanich K, Yongprawat T, Jindawong N, Chansakul C. Bangkok Med J. 2018; 14:10-5.

[29] Walter SD, Eliasziw M, Donner A. Sample size and optimal designs for reliability studies. Stat Med. 1998; 17:101-10.

[30] Cicchetti DV. Guidelines, criteria, and rules of thumb for evaluating normed and standardized assessment instruments in psychology. Psychol Assess. 1994; 6:284-90.

[31] D’Amico D, Mosconi P, Genco S, Usai S, Prudenzano AM, Grazzi L, et al. The migraine disability assessment (MIDAS) questionnaire: translation and reliability of the Italian version. Cephalalgia. 2001; 21:947-52.

[32] Iigaya M, Sakai F, Kolodner KB, Lipton RB, Stewart WF. Reliability and validity of the Japanese migraine disability assessment (MIDAS) Questionnaire. Headache. 2003; 43:343-52.

[33] Ertaş M, Siva A, Dalkara T, Uzuner N, Dora B, İnan L, et al; Turkish MIDAS group. Validity and reliability of the Turkish migraine disability assessment (MIDAS) questionnaire. Headache. 2004; 44:786-93.

[34] Gedikoglu U, Coskun O, Inan LE, Ucler S, Tunc T, Emre U. Validity and reliability of Turkish translation of migraine disability assessment (MIDAS) questionnaire in patients with migraine. Cephalalgia. 2004; 25:452-6.

[35] Hung PH, Fuh JL, Wang SJ. Validity, reliability and application of the Taiwan version of the migraine disability assessment questionnaire. J Formos Med Assoc. 2006; 105:563-8.

[36] Mourad D, Hajj A, Hallit S, Ghossoub M, Khabbaz LR. Validation of the Arabic version of the migraine disability assessment scale among Lebanese patients with migraine. J Oral Facial Pain Headache. 2019; 33:47-53.

[37] Oikonomidi T, Vikelis M, Artemiadis A, Chrousos GP, Darviri C. Reliability and validity of the Greek migraine disability assessment (MIDAS) questionnaire. Pharmacoecon Open. 2018; 2:77-85.

[38] Benz T, Lehmann S, Gantenbein AR, Sandor PS, Stewart WF, Elfering A, et al. Translation, cross-cultural adaptation and reliability of the German version of the migraine disability assessment (MIDAS) questionnaire. Health Qual Life Outcomes. 2018; 16:42. doi: 10.1186/s12955-018-0871-5

[39] Rodríguez-Almagro D, Achalandabaso A, Rus A, Obrero-Gaitán E, Zagalaz-Anula N, Lomas-Vega R. Validation of the Spanish version of the migraine disability assessment questionnaire (MIDAS) in university students with migraine. BMC Neurol. 2020; 20:67. doi: 10.1186/s12883-020-01646-y

[40] Sousa VD, Rojjanasrirat W. Translation, adaptation and validation of instruments or scales for use in cross-cultural health care research: a clear and user-friendly guideline. J Eval Clin Pract. 2011; 17: 268-74. 